\title{
Huge pyometra in a postmenopausal age: a diagnostic dilemma
}

\author{
Pramila Yadav*, Nikhil Datar, Pabashi Poddar, Komal Chavan, Rajendra Saraogi
}

Department of Obstetrics \& Gynaecology, DR R N Cooper Hospital, Mumbai, India

Received: 27 August 2015

Accepted: 09 September 2015

\author{
*Correspondence: \\ Dr. Pramila Yadav, \\ E-mail: pramila411@gmail.com
}

Copyright: (C) the author(s), publisher and licensee Medip Academy. This is an open-access article distributed under the terms of the Creative Commons Attribution Non-Commercial License, which permits unrestricted non-commercial use, distribution, and reproduction in any medium, provided the original work is properly cited.

\begin{abstract}
Pyometra in postmenopausal women is an extremely rare disease that hardly responds to the usual treatment of antibiotics therapy. Our case presented as a postmenopausal woman with a huge pyometra. Pyometra drainage was done with great difficulty after a blind biopsy. Endometrial and cervical biopsy followed by endometrial curettage was done. An intrauterine foley's catheter was kept for seven days and Histopathological report was suggestive of squamous cell carcinoma of cervix.
\end{abstract}

Keywords: Pyometra, Squamous cell carcinoma cervix

\section{INTRODUCTION}

Pyometra, an accumulation of pus in the uterine cavity, is an uncommon condition that has a reported incidence of $0.01 \%-0.5 \%$ in gynaecologic patients. ${ }^{1}$ The incidence of pyometra increases with age and indeed its incidence is $13.6 \%$ in elderly patients. Median age of presentation is 65 years and less than one-third cases are associated with underlying malignancy. ${ }^{2}$ Other causes being foreign bodies, puerperal infections or uterine anomalies. ${ }^{3}$ However, it is thought to be relatively rare in the premenopausal age group. Pyometra may present as purulent vaginal discharge and lower abdominal pain. It may rarely present as a spontaneous rupture of pyometra with significant morbidity and mortality. ${ }^{3}$ Treatment of choice is dilatation of the cervix and drainage of pus under adequate antibiotic cover. ${ }^{1}$

\section{CASE REPORT}

A 72 years P7L7, tubectomy done, postmenopausal since more than 20 years with previous normal menses came with complains of pain in lower abdomen and slowly growing mass per abdomen over the last 3 months. She had developed reduced appetite, constipation and burning micturition over the last 2 months. There was no history of per vaginal bleeding, discharge and pyuria. She was a known hypertensive not on any medication and diabetes on oral hypoglycemics. On examination breast and vitals were stable. Per abdomen uterus was 24 weeks more towards left side, regular, mobile, firm and nontender. On per speculum Vagina was healthy and Cervix could not be visualized. On per vaginum, a 24 weeks cystic mass was felt with a groove felt between mass and uterus, mobile, deviated to left side. Uterus appeared normal in size. Clinical impression of a penduculated subserosal fibroid with degenerative changes was made.

Patient was admitted and investigated to find the aetiology. She had Haemoglobin of $11.7 \mathrm{gm} \%$ with a CBC 8800 and RFT LFT was within normal limits. CA $12516.87 \mathrm{U} / \mathrm{ml}$ and CEA was 3.16ng/ml. Chest X Ray and ECG was normal. USG Pelvis showed a cystic lesion with echoes within measuring 16x8x14 cm. Uterus and ovaries could not be visualised separately from lesion. A radiological impression of haematometra or an ovarian cyst was made. CT Abdomen was normal. CT pelvis showed an enlarged uterus of $18 \times 9 \times 8 \mathrm{~cm}$ with thinned out uterine walls reaching up to left lieno renal pouch in the lower abdomen. Moderate to severe low echoeic fluid 
was present in uterine cavity measuring approximately $400 \mathrm{ml}$ suggestive of hematometra. Cervix appeared significantly hypertrophied.

2D ECHO Cardiography and colour Doppler study showed fair LV Systolic function, LVEF 50-55\%, Hypokinesia of posterior wall of LV, Grade $1 \mathrm{MR}$ and Mild Diastolic dysfunction, no significant PH and LVH. Patient was posted for EUA and pyometra drainage with exploratory laprotomy sos TAH BSO and sos omentectomy.

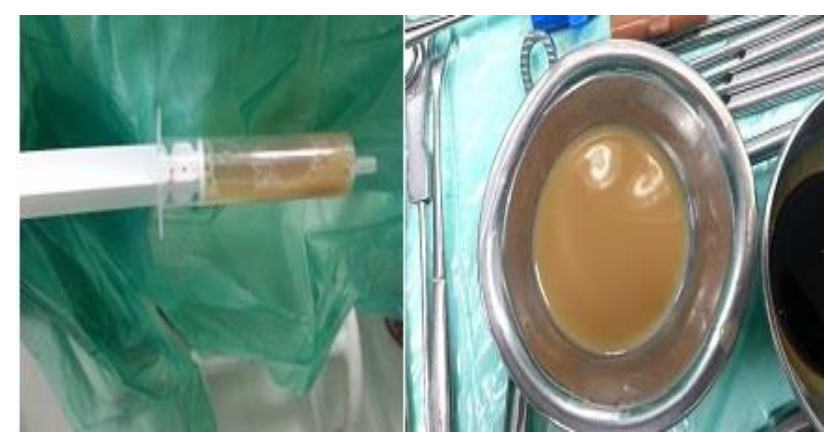

Figure 1: Drained pyometra.

Under spinal anaesthesia, same findings were confirmed. A blind biopsy of the cervix was taken and sterile pyometra of approximately $500 \mathrm{ml}$ was drained and sent for culture and sensitivity test and an intrauterine foleys catheter was kept for drainage of pyometra. Diagnostic Laparoscopy showed normal uterus and tube \& both ovary. Endometrial curettage was done and sample sent for histopathology and TB PCR. Culture and sensitivity report showed necrosis and polymorphs was negative for TB PCR.

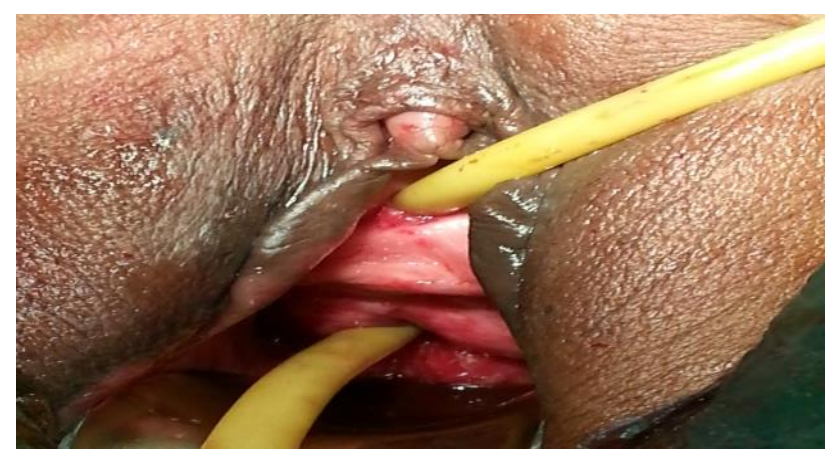

Figure 2: Intrauterine foleys.

Histopathological report of Cervix biopsy and endometrial sample was suggestive of Squamous Cell Carcinoma. Patient was postoperative stable for 24 hours but developed Transient Ischemic attack and was shifted to SICU and started on aspirin and antihypertensives. Insulin was omitted and low dose oral Hypoglycemics were started. Intrauterine Foleys Catheter was kept for 7 days. The drain was NIL and hence removed after the biopsy report confirmed the carcinoma. MRI Scan of brain plain showed chronic ischemic changes. There were no further TIA episodes and decision to refer to Tata Memorial Hospital for radiotherapy was done in view of associated co-morbities.

\section{DISCUSSION}

Pyometra is the accumulation of purulent material in the uterine cavity. Pyometra is an uncommon condition, but the incidence of associated malignancies is considerable. The common causes of pyometra in postmenopausal women are malignancies of genital tract and the consequence of their treatment (radiotherapy). Other postmenopausal causes are benign tumor-like leiomyomas, endometrial polyps, senile cervicitis and cervical occlusion after surgery or idiopathic conditions. $22.2 \%$ of the cases are associated with malignancy, $3.7 \%$ with genital tract abnormality and $74.1 \%$ were idiopathic. The classic triad of symptoms in patients with pyometra consists of purulent vaginal discharge, postmenopausal bleeding and lower abdominal pain. Symptoms being nonspecific, the diagnosis of pyometra is difficult unless suspected and specifically looked for. Once diagnosed, a careful history and a detailed pelvic examination should be performed to rule out associated malignancies. Pyometra is a serious medical condition, because of both its association with malignant diseases and the danger of spontaneous perforation. ${ }^{4}$ Dilatation of the cervix and pus drainage is the treatment of choice, and it is important to rule out the possibility of cancer and differentiate the malignancy. Once the diagnosis of malignancy is made after drainage of pyometra, radiotherapy needs to be given as uterus is refractory prior to drainage.

\section{CONCLUSION}

Every consultation is an opportunity for health education and promotion. Patients need to be encouraged to utilize cervical screening programmes. It is also important to remember that cervical cancer can present with nonspecific symptoms hence it should always be kept in mind during evaluation of such cases. However other differential diagnosis should also not be neglected. An early diagnosis and prompt treatment followed by radiotherapy is ideal management of choice for such patients.

\section{Funding: No funding sources Conflict of interest: None declared Ethical approval: Not required}

\section{REFERENCES}

1. Lee DH, Cho DH, Lee JH, Kim YR. A case of postmenopausal pyometra caused by endometrial tuberculosis. Korean J Obstet Gynecol. 2012;55(6):429-32.

2. Chauhan SCA, Sharma LCMM, Banerjee BJK. Spontaneous perforation of pyometra: A rare cause of diffuse peritonitis; Medical Journal armed forces India. 2015;71:192-3. 
3. Singhal M, Tanwar R, Kumar A, Prasad S. A Rare Case of Tuberculosis Pyometra in a Young Infertile Female Confirmed by mRNA-based RT-PCR, Journal of Family and Reproductive Health. 2012;6(3).

4. Agarwal R, Suneja A, Sharma A, Vaid NB. An Unusual Etiology of Spontaneous Pyometra
Perforation: a case report, J Reprod Infertil. $2011 ; 12(3): 235-8$

Cite this article as: Yadav P, Datar N, Poddar P, Chavan K, Saraogi R. Huge pyometra in a postmenopausal age: a diagnostic dilemma. Int $\mathrm{J}$ Reprod Contracept Obstet Gynecol 2015;4:1549-51. 